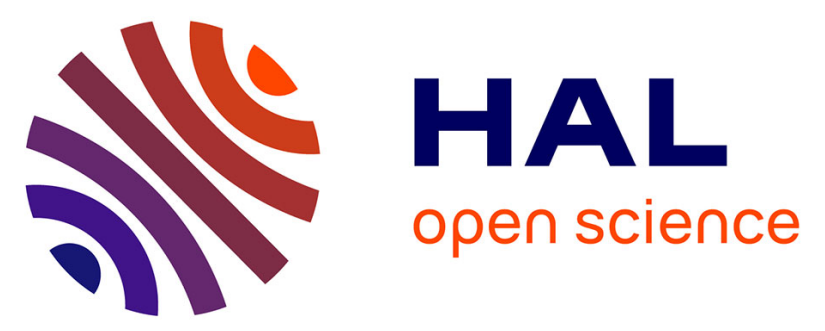

\title{
Serum adiponectin is related to plasma high-density lipoprotein cholesterol but not to plasma insulin-concentration in healthy children: the FLVS II study.
}

Adrien Kettaneh, Barbara Heude, Jean-Michel Oppert, Philipp Scherer, David Meyre, Jean-Michel Borys, Pierre Ducimetière, Marie-Aline Charles

\section{To cite this version:}

Adrien Kettaneh, Barbara Heude, Jean-Michel Oppert, Philipp Scherer, David Meyre, et al.. Serum adiponectin is related to plasma high-density lipoprotein cholesterol but not to plasma insulinconcentration in healthy children: the FLVS II study.: Adiponectin in children. Metabolism, 2006, 55, pp.1171-6. 10.1016/j.metabol.2006.04.015 . inserm-00135191

\section{HAL Id: inserm-00135191 https://www.hal.inserm.fr/inserm-00135191}

Submitted on 4 Jun 2007

HAL is a multi-disciplinary open access archive for the deposit and dissemination of scientific research documents, whether they are published or not. The documents may come from teaching and research institutions in France or abroad, or from public or private research centers.
L'archive ouverte pluridisciplinaire HAL, est destinée au dépôt et à la diffusion de documents scientifiques de niveau recherche, publiés ou non, émanant des établissements d'enseignement et de recherche français ou étrangers, des laboratoires publics ou privés. 
Serum Adiponectin is Related to Plasma HDL-Cholesterol but not to Plasma InsulinConcentration in Healthy Children. The FLVS II Study.

ADRIEN KETTANEH, BARBARA HEUDE, JEAN-MICHEL OPPERT, PHILIPP

SCHERER, DAVID MEYRE, JEAN-MICHEL BORYS, PIERRE DUCIMETIERE, AND MARIE-ALINE CHARLES.

INSERM U 780 (A.K., B.H., P.D., M.A.C.), IFR 69, Faculté de Médecine Paris-Sud, Villejuif, France; Department of Nutrition (J.M.O.), Hotel-Dieu Hospital, EA 3502, University Paris VI, Paris, France; Departments of Cell Biology and Medicine, Diabetes Research and Training Center (P.S.), Albert Einstein College of Medicine, Bronx, NY 10461, USA; CNRS UMR 8090, Laboratoire Génétique des Maladies Multi-factorielles (D.M.), Institut de Biologie de Lille, 59019 Lille Cedex, France; ${ }^{5}$ Association Fleurbaix-Laventie Ville Santé, Laventie, France.

Abbreviated title: Adiponectin in children

Key-words: Adipose Tissue, Adolescents / Children, Cardiovascular Risk Factors, Lipids, Adiponectin

Address correspondence and reprint requests to:

Dr. M.A. Charles, INSERM U 258, 16 Avenue Paul Vaillant Couturier, 94807 Villejuif Cedex, France.

E-mail: charles@vjf.inserm.fr

Tel: $33(0) 145595105$ 
Fax: 33(0)1 47269454

Context: While low levels of plasma adiponectin were associated with an increase in cardiovascular risk in adults, few data investigated that relationship in children.

Objective: To investigate the relationship between plasma adiponectin and cardiovascular risk factors in healthy children.

Design: A cross-sectional population-based study.

Setting: Fleurbaix and Laventie, two cities in the North of France.

Main outcome measure: The correlations between plasma adiponectin and adiposity variables (the body mass index (BMI), the sum of 4 skinfolds (SSK), waist circumference (WC, and percent body fat (bioimpedance)), blood pressure, plasma glucose, triglycerides, HDL-cholesterol and insulin.

Results: In 398 children of both sexes, adiponectin was not significantly related to age and pubertal stage. In boys only, adiponectin correlated with WC $(r=-0.19 ; \mathrm{p}=0.008)$ and BMI $(r=-$ 0.15; $\mathrm{p}=0.04$ ) but not with other adiposity variables. After taking into account $\mathrm{WC}$, adiponectin was positively correlated with HDL-cholesterol in boys $(\mathrm{r}=0.14 ; \mathrm{p}=0.05)$ and girls $(\mathrm{r}=0.25 ; \mathrm{p}=0.0004)$ but was not correlated with insulin and HOMA index for insulin resistance (IR) in both sexes.

Conclusions: These results suggest that, in apparently healthy children, adiponectin is related to the level of HDL-cholesterol independently of fat mass. The relationship between adiponectin and insulin resistance previously reported in obese or diabetic children was not apparent in these subjects, and may therefore occur only at later age with fat accumulation. 
Adiponectin is a collagen-like plasma protein abundantly present in the circulation and secreted by mature adipocytes [1] which may increase insulin sensitivity, has antiinflammatory properties and anti-atherogenic effects [2]. In adults, decreased levels of plasma adiponectin were reported by case-control studies in obese subjects $[3,4]$ and patients with type 2 diabetes [5], hypertension [6], dyslipidemia [7] or cardiovascular disease [8]. In apparently healthy adults, an inverse relationship was shown between plasma adiponectin and adiposity [9], insulin resistance [10], and blood pressure [11]. Furthermore, reduced concentration of plasma adiponectin may predict subsequent development of type 2 diabetes, increase in triglycerides and decrease in HDL-cholesterol concentrations [5, 12].

During puberty plasma levels of adiponectin decline in boys, leading to reduced levels in adolescent boys compared to girls $[13,14]$. In children, cross-sectional studies reported an inverse relationship between the level of plasma adiponectin and body fat content [15] or the prevalence of obesity [16]. In children, plasma adiponectin has also been positively associated with the level of plasma HDL-cholesterol [17-19]. An inverse relationship between adiponectin and insulin has also been reported in children $[14,17]$. These data suggest that the relationship between adiponectin and some cardiovascular risk factors, including adiposity, insulin resistance and HDL-cholesterol may already be present in adolescence.

However, most of these data were obtained in samples including a high proportion of obese or diabetic children and little is known about the relationship between adiponectin and cardiovascular risk factors in healthy children from populations with low overweight prevalence. Furthermore cardiovascular risk factors are related with each other and whether adiponectin is precociously associated with some of them independently of others has still to be determined. 
The aim of this study was to describe the relationships between adiponectin and markers of cardiovascular risk (including adiposity) in apparently healthy children from the general population

\section{Subjects and Methods}

\section{Participants}

The subjects were participants in the Fleurbaix-Laventie Ville Santé II (FLVS II) study, the purpose of which was to investigate genetic, metabolic and environmental determinants of weight gain in two small cities in Northern France. In 1999, FLVS II was proposed to the families who had previously participated in Phase I of the study (FLVS I) which consisted in the clinical follow-up of children involved in a 5-year nutritional education program at school [20]. Among the 393 families who were still living in the area and could be contacted, 294 agreed to participate. The entire assessment protocol on adiposity measurements at inclusion in 1999 was completed by 508 children aged 8-18, of which 398 had a determination of biological parameters including plasma adiponectin.

The study protocol of FLVS II had been approved by the ethic committee of Lille on July 1998 and the data files have been declared to the "Commission Nationale Informatique et Liberté".

\section{Measurements}

Clinical examinations at inclusion in 1999 were performed at home by 6 trained physicians. Height (to the nearest $5 \mathrm{~mm}$ ) was measured with a stadiometer. Weight (to the nearest $0.1 \mathrm{~kg}$ ), and body composition were determined barefoot, in light clothes with a Tanita $^{\circledR}$ TBF 310 body fat analyser (Tanita Corp, France). Overweight and obesity were defined using age and sex related BMI cut-off points established by Cole et al. [21] from the 
pooling of 6 large nationally representative growth studies in children. Briefly these cut-offs were drawn from centiles curves obtained that at age 18 passed through the cut-off points of 25 and $30 \mathrm{~kg} / \mathrm{m} 2$ which define overweight and obesity in adults. The bicipital, tricipital, suprailiac and subscapular skinfolds were measured twice (to the nearest $0.1 \mathrm{~mm}$ ) with a Harpenden caliper and the average of the two measurements was used in analyses. Waist circumference (WC) was recorded to the nearest $5 \mathrm{~mm}$ at midpoint between the iliac crest level and the lowest rib on the midaxillary line. In a sample of 64 children, reproducibility of two measures performed one week apart, was similar for skinfolds, waist circumference and BIA \% fat measurements (intraclass correlation coefficient: 0.979-0.992). Correlation coefficient between percent body fat assessed by bioimpedance and anthropometric variables (skinfolds and waist circumference) was higher than 0.70 in children of both sexes [22]. Pubertal stage was recorded according to the Tanner classification [23].

A $20 \mathrm{ml}$ fasting venous blood sample was drawn at inclusion in 1999 for measurement of plasma glucose, triglycerides, HDL-cholesterol, insulin (Bi-Insulin IRMA, Kit Sanofi Pasteur, France). Total plasma adiponectin concentration was measured from frozen samples in 2004 (Adiponectin RIA, kit HADP-61HK, Linco Research, St Louis, MO). HOMA fasting index for insulin resistance [24] was calculated.

\section{Statistical analysis}

The analysis was conducted separately in boys and girls. We compared characteristics between genders, and between subjects included or not in the analysis with Student $t$ test and Pearson's chi square test.

The relationships between adiponectin and each of the other variables were studied by gender and expressed as correlation coefficients, in each gender separately. To adjust for age and pubertal stage, these coefficients were estimated through a 2-step procedure. In the first 
step, we performed, in each gender separately, mixed linear models with adiponectin or other biologic or anthropometric variables as the dependent variable, and adjusted for age, pubertal stage, (and height if the dependent variable was waist or hip circumference), as the independent variables declared as fixed effect. As the recruitment of participants was based on family units and included siblings, a nuclear family variable was added to the models as a random effect variable to adjust for correlations between siblings. In the second step, we correlated the residuals of these regression models to obtain partial correlation coefficients between adiponectin and the considered variable which had been adjusted for confounding factors in step 1. For adiponectin, BMI and skinfolds, insulin and triglycerides measurements, and HOMA index of insulin resistance, a logarithmic transformation was performed because of a skewed distribution.

All analyses were performed with the $\mathrm{SAS}^{\circledR}$ statistical package (version 8.2, SAS, Cary, $\mathrm{NC})$.

\section{Results}

Population characteristics (Table 1)

We have excluded from the analysis, 110 subjects for whom adiponectin measurements had not been performed. Excluded subjects were on average younger than in the study population especially for girls $(12.7 \pm 2.6$ versus $13.6 \pm 2.6 \mathrm{y} ; \mathrm{p}=0.02)$. After adjustment for age, excluded subjects had similar anthropometric characteristics compared to subjects retained in the analyses (results not shown). Characteristics of study subjects (Table 1) showed expected gender differences for adiposity and pubertal stage. Plasma fasting glucose, triglycerides, and 
insulin were higher in girls than in boys (all $\mathrm{p}$ values $<0.03$ ). Mean systolic blood pressure was higher in boys than in girls. Plasma adiponectin was significantly higher in girls compared to boys.

Relationship between plasma adiponectin, age and pubertal stage (Table 2)

The logarithm of adiponectin concentration decreased with age in boys $\left(\beta=-0.045 \mu \mathrm{g} . \mathrm{ml}^{-}\right.$ ${ }^{1}(95 \% \mathrm{CI}:-0.07 ;-0.02)$ per 1 y increase; $\left.\mathrm{p}=0.0003\right)$ in boys but not in girls $\left(\beta=-0.004 \mu \mathrm{g} . \mathrm{ml}^{-1}\right.$ (95\%CI: $-0.02 ; 0.017)$ per 1 y increase; $p=0.73$ ) and mean concentration of adiponectin tended to decrease with puberty in boys (Table 2).

In both genders, the relationship between adiponectin and age did not differ according to pubertal stage and was not significant after adjusting for pubertal stage.

Relationships between plasma adiponectin, metabolic variables and blood pressure (Tables 3 and 4)

The relationships between plasma adiponectin and cardiovascular risk factors did not vary significantly according to pubertal status (results not shown). After adjustment for age and pubertal stage, there was a negative correlation, in boys only, between plasma adiponectin and $\mathrm{BMI}(\mathrm{R}=-0.15 ; \mathrm{p}=0.04)$ and $\mathrm{WC}(\mathrm{R}=-0.19 ; \mathrm{p}=0.008)$ (Table 3). Plasma adiponectin was not correlated with insulin or HOMA IR index in either gender but there was a trend for a negative correlation with plasma glucose in girls $(\mathrm{R}=-0.14 ; \mathrm{p}=0.06)$. There was a positive correlation between plasma adiponectin and HDL-cholesterol in both sexes (boys: $\mathrm{r}=0.18$; $\mathrm{p}=0.009$; girls: $\mathrm{r}=0.26 ; \mathrm{p}=0.0003)$, and, in girls, a negative correlation with triglycerides $(\mathrm{r}=-$ $0.19 ; \mathrm{p}=0.01)$.

After additional adjustment for WC, plasma adiponectin concentrations remained correlated with HDL-cholesterol in girls $(r=0.25 ; p=0.0004)$ and boys $(r=0.14 ; p=0.05)$ and with triglycerides in girls only $(\mathrm{r}=-0.17 ; \mathrm{p}=0.02)$ (Table 4$)$. In these models, WC was 
significantly associated with all biological variables (except fasting glucose in boys) and with diastolic blood pressure in girls, independently from adiponectin.

\section{Discussion}

We identified an inverse relationship between plasma adiponectin concentration and several adiposity markers in a population of apparently healthy children with less than $10 \%$ of overweight. However this relationship was weak and significant only in boys, particularly with WC, an indicator of abdominal fat accumulation. These findings are consistent with previous data reported in children $[15,17,18]$. Cnop et al. [25] identified in adults, a negative correlation between adiponectin and CT-assessed intra-abdominal fat, whether they found no relationship with subcutaneous fat. Therefore total adipose mass is probably not a main determinant factor for plasma adiponectin concentration or activity, the decrease of which may only be related to a high amount of intra-abdominal fat. A lower amount of fat stored in the intra-abdominal compartment may explain that the strength of the relationship between adiponectin and total fat mass in children tended to be weaker in our study than in other reports with higher prevalence of overweight or obese subjects $[15,18,19]$. The fact that plasma adiponectin was measured from frozen samples may also have contributed to weaken some of the relationships assessed in our sample. However, unexpectedly Looker et al. [26] observed a positive correlation between storage time and serum adiponectin in frozen sera. However this correlation was significant only among subjects with diabetes, and no relationship was disclosed in healthy subjects. In our sample of healthy children, storage time, about 5 years, did not vary substantially among subjects. Therefore we do not believe that the relationships we have observed are confounded by storage time of samples. 
The inverse relationship between adiponectin and insulin, identified in apparently healthy adults [4], has also been reported in children $[14,17]$. However our results, in line with other studies $[15,27,28]$, do not confirm these findings. These discrepancies may partly be explained by different adjustment methods for adiposity, age and pubertal stage, or distinct methods for plasma adiponectin measurement. The relationship between adiponectin and insulin may also only be apparent in overweight subjects, and particularly in those with a high amount of visceral fat. Experimental data on several models of knockout mice suggest a protective effect of adiponectin on insulin resistance induced by a high fat diet [29]. Administration of recombinant adiponectin in mice resulted in a transient decrease in plasma glucose without change in insulin concentration [30].Recombinant adiponectin may however not reflect the full range of metabolic effects of that hormone. The main target of adiponectin in muscular tissue is AMP-activated protein kinase [31], which is involved in insulin sensitivity. Plasma adiponectin is negatively correlated to skeletal muscle lipid content [32] and increases fatty acid oxidation in muscle through activation of the AMP-dependent kinase pathway [33]. It is therefore possible that the decrease in insulin sensitivity associated with low adiponectin concentration occurs late in the course of obesity development due to both a decrease of adiponectin production by enlarged intra-abdominal adipocytes and an accumulation of triglycerides in muscle cells due to decreased fatty acid oxidation.

In the blood stream, the full-length form of adiponectin forms high molecular weight oligomers, each of which may have distinct signalling properties [30, 34]. The different forms of circulating adiponectin may change between childhood and adulthood depending on other factors. This may explain part of the discrepancies between results of studies measuring total circulating adiponectin, as ours. Recent publications have confirmed different actions of the different forms of circulating adiponectin on insulin sensitivity. Yamauchi et al. showed that full-length but not globular adiponectin activates the 5'-AMP-activated protein kinase 
involved in gluconeogenesis in the liver [35], and identified a protective effect of globular adiponectin in vivo against insulin resistance in ob/ob mice [36]. The ratio between high molecular and relative low molecular weight isoforms (Sa index) rather than absolute amount of adiponectin may then be critical in determining insulin sensitivity [34].

The weak relationship between total plasma adiponectin and adiposity or insulin, contrasts with the stronger relationship with HDL-cholesterol, suggesting that the association of adiponectin on lipids is independent of the amount of fat mass and insulin levels. As in a previous report in apparently healthy children and adolescents [19] we observed a relationship of plasma adiponectin concentration with blood lipids, mainly with HDL-cholesterol but also with triglycerides, even after taking into account central adiposity. In adult men, a negative correlation was identified between plasma adiponectin and VLDL-apoB, a pool of triglycerides-rich lipoproteins, whether a positive correlation was identified with HDLcholesterol and VLDL-apoB catabolism [37]. However, the mechanisms explaining the relationship between adiponectin and serum HDL-cholesterol concentration are still poorly understood. In contrast to the relationship with fat mass and insulin sensitivity, mainly seen in the obese or diabetic state, the association between adiponectin and lipids can be seen across the whole range of the fat mass distribution in the population and is already present in childhood.

If adipocytes are by far the main source of circulating adiponectin, the lack of, or weak relationship between total or regional fat mass measurements and adiponectin concentration in our sample, may also suggest that other features may be prominent to explain the variability of adiponectin concentration and effects in children. Bottner et al. [13] identified in lean boys a decline in adiponectin levels parallel to pubertal development inversely related to testosterone and dehydroepiandrostenedione serum concentrations. Adiponectin concentration 
is higher in hypogonadal than in eugonadal adult men, and is decreased by testosterone replacement therapy in the formers [38]. These data suggest that sexual hormones are important determinants for adiponectin concentration and recent data demonstrated that expression of adiponectin circulating forms is as well regulated by sexual hormones in rodents and humans [39]. In adolescents, the differential relationship of adiponectin with fat mass and distribution or with insulin sensitivity may therefore be related to variability in the adiponectin concentration of the different circulating forms due to increasing sexual hormones.

In conclusion, our results indicate that associations of adiponectin with blood lipid and especially HDL-cholesterol concentrations are already present in children and do not depend on adiposity or insulin sensitivity. The decrease in insulin sensitivity associated with low adiponectin concentration may therefore occur only later in the course of fat mass accumulation, in contrast with the early association between adiponectin and lipids that is seen across the whole range of fat mass distribution in the population.

\section{Acknowledgments}

We thank the families, school teachers, general practitioners and city officials of Fleurbaix and Laventie who made the study possible and Agnès Lommez for supervising the data collection. .This study was supported by Knoll, CEDUS, Groupe Fournier, Lesieur, Nestlé France, Produits Roche and CISB. MA Charles was the recipient of grants from the French Speaking Association for the Study of Diabetes and Metabolism (ALFEDIAM) and from the Mutuelle Générale de l'Education Nationale (MGEN). 


\section{References}

1. Scherer PE, Williams S, Fogliano M, Baldini G, Lodish HF. A novel serum protein similar to c1q, produced exclusively in adipocytes. J Biol Chem 270: 26746-26749, 1995

2. Goldstein BJ, Scalia R. Adiponectin: A novel adipokine linking adipocytes and vascular function. J Clin Endocrinol Metab 89: 2563-2568, 2004

3. Arita Y, Kihara S, Ouchi N, et al. Paradoxical decrease of an adipose-specific protein, adiponectin, in obesity. Biochem Biophys Res Commun 257: 79-83, 1999

4. Matsubara M, Maruoka S, Katayose S. Inverse relationship between plasma adiponectin and leptin concentrations in normal-weight and obese women. Eur J Endocrinol 147: 173-180, 2002

5. Lindsay RS, Funahashi T, Hanson RL, et al. Adiponectin and development of type 2 diabetes in the pima indian population. Lancet 360: 57-58, 2002

6. Adamczak M, Wiecek A, Funahashi T, Chudek J, Kokot F, Matsuzawa Y. Decreased plasma adiponectin concentration in patients with essential hypertension. Am J Hypertens 16: $72-75,2003$

7. Matsubara M, Maruoka S, Katayose S. Decreased plasma adiponectin concentrations in women with dyslipidemia. J Clin Endocrinol Metab 87: 2764-2769, 2002 
8. Dzielinska Z, Januszewicz A, Wiecek A, et al. Decreased plasma concentration of a novel anti-inflammatory protein--adiponectin--in hypertensive men with coronary artery disease. Thromb Res 110: 365-369, 2003

9. Kazumi T, Kawaguchi A, Hirano T, Yoshino G. Serum adiponectin is associated with highdensity lipoprotein cholesterol, triglycerides, and low-density lipoprotein particle size in young healthy men. Metabolism 53: 589-593, 2004

10. Matsubara M, Katayose S, Maruoka S. Decreased plasma adiponectin concentrations in nondiabetic women with elevated homeostasis model assessment ratios. Eur $\mathrm{J}$ Endocrinol 148: 343-350, 2003

11. Kazumi T, Kawaguchi A, Sakai K, Hirano T, Yoshino G. Young men with high-normal blood pressure have lower serum adiponectin, smaller ldl size, and higher elevated heart rate than those with optimal blood pressure. Diabetes Care 25: 971-976, 2002

12. Choi KM, Lee J, Lee KW, et al. Serum adiponectin concentrations predict the developments of type 2 diabetes and the metabolic syndrome in elderly koreans. Clin Endocrinol (Oxf) 61: 75-80, 2004

13. Bottner A, Kratzsch J, Muller G, et al. Gender differences of adiponectin levels develop during the progression of puberty and are related to serum androgen levels. J Clin Endocrinol Metab 89: 4053-4061, 2004 
14. Tsou PL, Jiang YD, Chang CC, et al. Sex-related differences between adiponectin and insulin resistance in schoolchildren. Diabetes Care 27: 308-313, 2004

15. Stefan N, Bunt JC, Salbe AD, Funahashi T, Matsuzawa Y, Tataranni PA. Plasma adiponectin concentrations in children: Relationships with obesity and insulinemia. J Clin Endocrinol Metab 87: 4652-4656, 2002

16. Weiss R, Dziura J, Burgert TS, et al. Obesity and the metabolic syndrome in children and adolescents. N Engl J Med 350: 2362-2374, 2004

17. Nemet D, Wang P, Funahashi T, et al. Adipocytokines, body composition, and fitness in children. Pediatr Res 53: 148-152, 2003

18. Diamond FB, Jr., Cuthbertson D, Hanna S, Eichler D. Correlates of adiponectin and the leptin/adiponectin ratio in obese and non-obese children. J Pediatr Endocrinol Metab 17: 1069-1075, 2004

19. Huang KC, Lue BH, Yen RF, et al. Plasma adiponectin levels and metabolic factors in nondiabetic adolescents. Obes Res 12: 119-124, 2004

20. Lafay L, Basdevant A, Charles MA, et al. Determinants and nature of dietary underreporting in a free-living population: The fleurbaix laventie ville sante (flvs) study. Int J Obes Relat Metab Disord 21: 567-573, 1997 
21. Cole TJ, Bellizzi MC, Flegal KM, Dietz WH. Establishing a standard definition for child overweight and obesity worldwide: International survey. Bmj 320: 1240-1243, 2000

22. Kettaneh A, Heude B, Lommez A, Borys JM, Ducimetière P, Charles MA. Reliability of bioimpedance analysis compared with other adiposity measurements in children: The flvs ii study. Diabetes Metab 31: 534-541, 2005

23. Tanner JM. The assessment of growth and development in children. Arch Dis Child 27: $10-33,1952$

24. Matthews DR, Hosker JP, Rudenski AS, Naylor BA, Treacher DF, Turner RC. Homeostasis model assessment: Insulin resistance and beta-cell function from fasting plasma glucose and insulin concentrations in man. Diabetologia 28: 412-419, 1985

25. Cnop M, Havel PJ, Utzschneider KM, et al. Relationship of adiponectin to body fat distribution, insulin sensitivity and plasma lipoproteins: Evidence for independent roles of age and sex. Diabetologia 46: 459-469, 2003

26. Looker HC, Krakoff J, Funahashi T, et al. Adiponectin concentrations are influenced by renal function and diabetes duration in pima indians with type 2 diabetes. J Clin Endocrinol Metab 89: 4010-4017, 2004

27. Silha JV, Krsek M, Skrha JV, Sucharda P, Nyomba BL, Murphy LJ. Plasma resistin, adiponectin and leptin levels in lean and obese subjects: Correlations with insulin resistance. Eur J Endocrinol 149: 331-335, 2003 
28. Vikram NK, Misra A, Pandey RM, Dwivedi M, Luthra K. Adiponectin, insulin resistance, and c-reactive protein in postpubertal asian indian adolescents. Metabolism 53: 1336-1341, 2004

29. Combs TP, Pajvani UB, Berg AH, et al. A transgenic mouse with a deletion in the collagenous domain of adiponectin displays elevated circulating adiponectin and improved insulin sensitivity. Endocrinology 145: 367-383, 2004

30. Berg AH, Combs TP, Du X, Brownlee M, Scherer PE. The adipocyte-secreted protein acrp30 enhances hepatic insulin action. Nat Med 7: 947-953, 2001

31. Yamauchi T, Kamon J, Ito Y, et al. Cloning of adiponectin receptors that mediate antidiabetic metabolic effects. Nature 423: 762-769, 2003

32. Weiss R, Dufour S, Groszmann A, et al. Low adiponectin levels in adolescent obesity: A marker of increased intramyocellular lipid accumulation. J Clin Endocrinol Metab 88: 20142018,2003

33. Gil-Campos M, Canete R, Gil A. Hormones regulating lipid metabolism and plasma lipids in childhood obesity. Int J Obes Relat Metab Disord 28 Suppl 3: S75-80, 2004

34. Pajvani UB, Hawkins M, Combs TP, et al. Complex distribution, not absolute amount of adiponectin, correlates with thiazolidinedione-mediated improvement in insulin sensitivity. $\mathrm{J}$ Biol Chem 279: 12152-12162, 2004 
35. Yamauchi T, Kamon J, Minokoshi Y, et al. Adiponectin stimulates glucose utilization and fatty-acid oxidation by activating amp-activated protein kinase. Nat Med 8: 1288-1295, 2002

36. Yamauchi T, Kamon J, Waki H, et al. Globular adiponectin protected ob/ob mice from diabetes and apoe-deficient mice from atherosclerosis. J Biol Chem 278: 2461-2468, 2003

37. Ng TW, Watts GF, Farvid MS, Chan DC, Barrett PH. Adipocytokines and vldl metabolism: Independent regulatory effects of adiponectin, insulin resistance, and fat compartments on vldl apolipoprotein b-100 kinetics? Diabetes 54: 795-802, 2005

38. Lanfranco F, Zitzmann M, Simoni M, Nieschlag E. Serum adiponectin levels in hypogonadal males: Influence of testosterone replacement therapy. Clin Endocrinol (Oxf) 60: $500-507,2004$

39. $\mathrm{Xu} \mathrm{A}$, Chan $\mathrm{KW}$, Hoo RL, et al. Testosterone selectively reduces the high molecular weight form of adiponectin by inhibiting its secretion from adipocytes. J Biol Chem 280: 18073-18080, 2005 
Table 1. Characteristics of study subjects

\begin{tabular}{|c|c|c|c|}
\hline & Boys & Girls & $\mathrm{P}$ \\
\hline $\mathrm{N}$ & 204 & 194 & \\
\hline Age (y) & $13.7 \pm 2.4$ & $13.6 \pm 2.6$ & 0.88 \\
\hline \multicolumn{4}{|l|}{ Tanner pubertal stage $(\%)$} \\
\hline 1 & 18.7 & 16.5 & \multirow{5}{*}{0.03} \\
\hline 2 & 18.7 & 11.9 & \\
\hline 3 & 18.7 & 20.6 & \\
\hline 4 & 31.0 & 28.4 & \\
\hline 5 & 12.8 & 22.7 & \\
\hline $\mathrm{BMI}\left(\mathrm{kg} \cdot \mathrm{m}^{-2}\right)$ & $18.5 \pm 3.2$ & $19.0 \pm 3.3$ & 0.15 \\
\hline Percent body fat & $13.3 \pm 6.5$ & $23.1 \pm 8.1$ & $<0.0001$ \\
\hline Sum of 4 skinfolds (mm) & $37.3 \pm 24.2$ & $49.3 \pm 23.0$ & $<0.0001$ \\
\hline Waist circumference $(\mathrm{cm})$ & $67.6 \pm 8.9$ & $65.1 \pm 7.7$ & 0.003 \\
\hline${ }^{a_{0}} \%$ overweight & $8.4 \%$ & $8.9 \%$ & $>0.99$ \\
\hline $\mathrm{a}_{0} \%$ obese & $1.5 \%$ & $2.1 \%$ & 0.72 \\
\hline Plasma adiponectin $\left(\mu \mathrm{g} \cdot \mathrm{ml}^{-1}\right)$ & $11.9 \pm 4.8$ & $13.5 \pm 5.1$ & 0.001 \\
\hline Plasma insulin (mUI. $\left.1^{-1}\right)$ & $5.5 \pm 3.0$ & $6.7 \pm 3.8$ & 0.0007 \\
\hline Plasma glucose $\left(\right.$ g. $\left.1^{-1}\right)$ & $0.86 \pm 008$ & $0.84 \pm 0.07$ & 0.01 \\
\hline HOMA index for insulin resistance & $1.18 \pm 0.76$ & $1.40 \pm 0.86$ & 0.006 \\
\hline Plasma triglycerides $\left(\mathrm{g} . \mathrm{l}^{-1}\right)$ & $0.63 \pm 0.27$ & $0.69 \pm 0.28$ & 0.02 \\
\hline Plasma HDL-cholesterol (g. $\left.1^{-1}\right)$ & $0.60 \pm 0.13$ & $0.60 \pm 0.12$ & 0.64 \\
\hline Systolic blood pressure $(\mathrm{mm} \mathrm{Hg})$ & $111 \pm 12.1$ & $105 \pm 11.4$ & $<0.0001$ \\
\hline Diastolic blood pressure $(\mathrm{mm} \mathrm{Hg})$ & $62 \pm 9.1$ & $62 \pm 8.9$ & 0.49 \\
\hline
\end{tabular}


Values are expressed as mean \pm SD or $\%$

${ }^{\mathrm{a}}$ According to age and sex related BMI cut-off points established by Cole et al.

$[21]$ 
Table 2. Mean plasma adiponectin concentrations $\left(\mu g . \mathrm{ml}^{-1}\right)$ according to Tanner pubertal stage in boys and girls

\begin{tabular}{|c|c|c|c|c|}
\hline & Boys & & Girls & \\
\hline & $\begin{array}{l}\text { Mean value } \\
(95 \% \mathrm{CI})\end{array}$ & P Value & $\begin{array}{l}\text { Mean value } \\
(95 \% \mathrm{CI})\end{array}$ & P Value \\
\hline Tanner 1 & $14.2(12.4 ; 16.2)$ & & $12.4(10.9 ; 14.2)$ & \\
\hline Tanner 2 & $11.6(10.2 ; 13.3)$ & & $13.5(11.5 ; 15.7)$ & \\
\hline Tanner 3 & $10.4(9.1 ; 11.9)$ & 0.0003 & $12.7(11.2 ; 14.3)$ & 0.27 \\
\hline Tanner 4 & $9.6(8.7 ; 10.7)$ & & $13.2(11.9 ; 14.6)$ & \\
\hline Tanner 5 & $9.8(8.4 ; 11.5)$ & & $11.2(10.0 ; 12.6)$ & \\
\hline
\end{tabular}

Plasma adiponectin was log-transformed

Results are given as the exponent of the mean value of log-adiponectin adjusted in mixed models taking into account a family variable as a random effect 
Table 3. Correlation coefficients ( $p$ value) between plasma adiponectin ${ }^{a}$ concentration and cardiovascular risk factors in boys and girls

\begin{tabular}{lccc}
\hline & Boys & Girls & P \\
& & & Value \\
\hline $\mathrm{N}$ & 204 & 194 & \\
${ }^{\mathrm{a}} \mathrm{BMI}$ & $-0.15(0.04)$ & $-0.07(0.33)$ & 0.42 \\
Percent body fat & $-0.09(0.20)$ & $0.03(0.69)$ & 0.23 \\
${ }^{\mathrm{a}}$ Sum of 4 skinfolds & $-0.10(0.14)$ & $-0.06(0.39)$ & 0.69 \\
Waist circumference & $-0.19(0.008)$ & $-0.06(0.43)$ & 0.05 \\
${ }^{\mathrm{a}}$ Plasma insulin & $-0.01(0.84)$ & $-0.01(0.87)$ & $>0.99$ \\
Plasma glucose & $-0.08(0.25)$ & $-0.14(0.06)$ & 0.55 \\
${ }^{\mathrm{a}} \mathrm{HOMA}$ index for insulin resistance & $-0.02(0.96)$ & $-0.03(0.65)$ & 0.92 \\
${ }^{\mathrm{a} P l a s m a}$ triglycerides & $-0.004(0.96)$ & $-0.19(0.01)$ & 0.06 \\
Plasma HDL-cholesterol & $0.18(0.009)$ & $0.26(0.0003)$ & 0.41 \\
Systolic blood pressure & $-0.06(0.36)$ & $-0.06(0.40)$ & $>0.99$ \\
Diastolic blood pressure & $-0.09(0.21)$ & $0.004(0.95)$ & 0.97 \\
\hline a & & & \\
\hline
\end{tabular}

${ }^{\mathrm{a}}$ Logtransformed

All variables were previously adjusted for age and pubertal stage by mixed models which took into account familial correlations as a random effect. Models with waist circumference included additional adjustment for height. 
Table 4. Partial correlation coefficients of plasma adiponectin and waist circumference (WC) adjusted on each other with metabolic variables and blood pressure

\begin{tabular}{lccccc}
\hline & \multicolumn{2}{c}{ Boys $(\mathrm{N}=204)$} & & \multicolumn{2}{c}{ Girls $(\mathrm{N}=194)$} \\
\cline { 2 - 3 } & Adiponectin & WC & & Adiponectin & WC \\
\hline Plasma glucose & $0.02(0.74)$ & $0.27(0.0001)$ & & $-0.005(0.95)$ & $0.31(<0.0001)$ \\
a & $-0.08(0.25)$ & $0.014(0.85)$ & & $-0.14(0.05)$ & $0.22(0.002)$ \\
a HOMA index for insulin & $0.01(0.87)$ & $0.26(0.0003)$ & & $-0.04(0.62)$ & $0.34(<0.002)$ \\
resistance & & & & $-0.17(0.02)$ & $0.30(<0.0001)$ \\
a Plasma triglycerides & $0.04(0.56)$ & $0.20(0.004)$ & & & \\
Plasma HDL-cholesterol & $0.14(0.05)$ & $-0.29(<0.0001)$ & & $0.25(0.0004)$ & $-0.15(0.04)$ \\
Systolic blood pressure & $-0.03(0.69)$ & $0.16(0.02)$ & & $-0.06(0.44)$ & $0.11(0.13)$ \\
Diastolic blood pressure & $-0.07(0.35)$ & $0.10(0.16)$ & & $0.02(0.77)$ & $0.26(0.0003)$
\end{tabular}

Values are give as partial correlation coefficients (significance level)

Adiponectin was logtransformed;

${ }^{a}$ Logtransformed

All models included both adiponectin and WC, and were adjusted for age, pubertal stage, and height, and took into account familial correlations as a random effect. 